\title{
DESIGN GRÁFICO DE IMPRESSOS EFÊMEROS - UM OLHAR SOBRE A PRODUÇÃO DE PANFLETOS ANTIGUERRA DO VIETNÃ EM SEATTLE
}

\author{
${ }^{1}$ Vivian Suarez Martins \\ Universidade Anhembi Morumbi \\ contato@vickasuarez.com \\ ${ }^{2}$ Agda Carvalho, Dra \\ Universidade Anhembi Morumbi
}

\begin{abstract}
Resumo: Este artigo analisa a produção de impressos efêmeros no período da Guerra do Vietnã, bem como o seu consequente desdobramento em manifestações populares. Os métodos escolhidos para a elaboração do artigo foram a pesquisa bibliográfica e o estudo do caso dos panfletos de Seattle e a Guerra do Vietnã (Vietnam Printed Ephemera). O trabalho propõe a reflexão sobre a relevância de peças gráficas impressas e a sua representatividade na propagação de mensagens, bem como traz um levantamento histórico e definições acerca do objeto de estudo selecionado. Desse modo, é feita a análise sobre a importância de impressos e como sua autonomia pode impactar na tomada de decisões governamentais e na sociedade, por meio de ações de mobilização social. A análise proposta traz exemplos de eventos de impacto e resultados alcançados.
\end{abstract}

Palavras-chave: design gráfico, impressos efêmeros, Guerra do Vietnã, manifestação popular.

\begin{abstract}
This article examines the production of printed ephemera in the period of the Vietnam War, as well as its subsequent unfolding in popular demonstrations. The methods chosen for its preparation were the literature review and the case study of the graphic material of Seattle in the Vietnam War (Vietnam Printed Ephemera). The article proposes a reflection on the role of the citizen/creative agent as a producer and disseminator of messages through the use of printed ephemera, and brings a historical survey and definitions on the topics presented. Thus, an analysis is made about the role of creator of printed and how autonomy can impact on society through social mobilization. The proposed analysis brings examples of impact actions and outcomes sought.
\end{abstract}

\footnotetext{
${ }^{1}$ Doutoranda e Mestre em Design pela Universidade Anhembi Morumbi. Certificada em sustentabilidade Global pela UCLA - Universitity of California, Los Angeles.

2 Doutora em Comunicação pela ECA-USP. Mestre em Artes Visuais pelo Instituto de Artes da UNESP. Artista plástica, pesquisadora de arte contemporânea.
} 
Keywords: graphic design, printed ephemera, Vietnam war, popular mobilization.

\section{INTRODUÇÃO}

O presente artigo foi elaborado com base em uma pesquisa bibliográfica e preliminar sobre os temas de design gráfico, impressos efêmeros e guerra do Vietnã. Constatou-se a lacuna no campo de pesquisas que contemplem os assuntos concomitantemente. Num segundo momento, a pesquisa dos termos isolados foi realizada, a fim de que fosse feita a coleta de informações por assunto, desde que contribuisse para a reflexão conjunta. Dentre os autores consultados na pesquisa bibliográfica, entre os principais estão Vizentini (1991), Arfuch (1997), Bonsiepe (2006), Manzini (2008) e Cardoso (2009).

O papel do design, em um contexto global, é construir cenários que estimulem a discussão e a inovação, contribuindo na regeneração dos aspectos sociais e ambientais da sociedade, e tem um papel formativo, educativo que permitirá à sociedade a ajustar-se a uma nova realidade (MANZINI, 2008). Porém, os projetos de design contemporâneos tendem a se afastar da ideia de resolução inteligente de problema e aproximam-se do efêmero, tornando-se rapidamente obsoletos (BONSIEPE, 2006). Segundo Kopp (2006):

Design gráfico é a complexa combinação de palavras e imagens, números e gráficos, fotografias e ilustrações que, para ter sucesso, demanda sua elaboração por parte de um particularmente cuidadoso indivíduo que pode orquestrar estes elementos de forma a eles se juntarem para formar algo distinto, ou útil, ou divertido ou surpreendente, ou subversivo, ou memorável." (KOPP, 2006, p. 42)

De acordo com Rafael Cardoso (2009), grande parte dos impressos é "efêmera", feito para ter uma vida curta, com exceção dos livros, de caráter mais permanente. A rigor, o termo "impressos efêmeros" ${ }^{3 "}$ refere-se a uma considerável gama de materiais que não pertence às categorias livro, revista, jornal, e nem às categorias colecionáveis como cartazes, selos, papel moeda e mapas. Efêmera é qualquer peça gráfica escrita ou impressa transitória, que não se destina a ser mantida ou preservada. Alguns impressos efêmeros, porém, podem se tornar itens de colecionadores, como cartas comerciais e folhetos publicitários, sacos de enjôo, marcadores, catálogos, cartões, folhetos, postais, cartazes, certificados de ações extintas ou bilhetes. Como diretrizes de investigação deste trabalho serão apresentados exemplos de impressos efêmeros criados e divulgados durante a Guerra do Vietnã.

O presente artigo aborda a relação do Design Gráfico e a produção dos impressos efêmeros, tendo como objeto de estudo impressos distribuídos entre 1965 e 1973, em Seattle, EUA, com temática relacionada à Guerra e questões acerca do tópico.

\footnotetext{
${ }^{3}$ Termo usado por pesquisadores de história gráfica para falar sobre os impressos avulsos que costumam ser descartados ou negligenciados, em relação aos cuidados recebidos por impressos mais 'nobres', como os livros. Em inglês, há vasta literatura e coleções sobre a printed ephemera.
} 


\section{O impresso efêmero, a mensagem, a mudança}

O design gráfico, efêmero ou permanente, entre outros, cria aparências. Porém, as aparências, sob a ação do tempo, tendem a se transformar, a morrer, a ressurgir. Uma vez caracterizado o designer como um estrategista de imagens e aparências, percebidas através dos sentidos, visuais acima de todos, a questão traz um conceito ambivalente: por um lado representa o domínio por meio da imagem, o brincar e a liberdade; por outro, a criação de aparências abre a discussão sobre o acesso do designer ao poder da manipulação (BONSIEPE, 2006).

Frascara (1997) traz à discussão a ideia de que as decisões intrínsecas ao processo do design se localizam no contexto das pessoas e o que se busca alcançar após a interação com as mensagens. A preocupação com questões sociais e com foco em mobilização surgem em discussões entre os próprios designers, cidadãos antes de qualquer ocupação. $O$ design socialmente orientado busca a mudança social por meio da mobilização. Apesar de o estudo de mudanças sociais fazer parte do universo da Sociologia, a busca pela definição de mudança social está longe de ser alcançada, e o termo em utilização refere-se a eventos e situações que remetam a modificações de uma sociedade e seus indivíduos (GOODWIN, 2010). No contexto da guerra do Vietnã e a massiva produção de impressos em Seattle, acerca do tema, a questão é: a participação do cidadão/criativo como propagador de mensagens contrárias à Guerra e às estrátegias governamentais surtiram efeito? A circulação de tais impressos impactou em tomadas de decisões dos governantes da época?

Leonor Arfuch (1997) sugere que, ao invés de inventariar-se os atributos que constituem a especificidade do design, vislumbre-se a possibilidade de dispersão, de diálogos, de entrecruzamentos em outras superfícies. Segundo a autora, é necessário pensar o design em sua pluralidade, como comunicação, imerso em redes de produção de sentido, onde a circulação é também crucial, suscetível de acentuações diferentes segundo casos e contextos. (ARFUCH, 1997). Na afirmação de Arfuch, então, respaldase a possibilidade de que a força dos impressos efêmeros apresentados no presente artigo está na sua circulação pela cidade de Seattle, Washington.

Segundo Vizentini (1991), o desenvolvimento dos meios de comunicação também foi decisivo para espalhar os ideais por todo o mundo e estimular a explosão de manifestações populares. No Brasil, em meio à ditadura militar, tais manifestações foram encarnadas pelo Tropicalismo. $O$ aparecimento da Aids, o término das utopias políticas e os violentos crimes associados às drogas deram fim às referências da contracultura, apesar de a cultura hippie continuar presente em ideais comunitários e nos livre compartilhamento na internet. De acordo com Evans e Kingsbury, o Festival de Woodstock ${ }^{4}$ esteve diretamente ligado aos protestos anti-guerra, por levantarem, em comum, a bandeira a favor da paz (EVANS e KINGSBURY, 2010). Durante três dias, em agosto de 1969, cerca de meio milhão de jovens idealistas assistiram a shows dos principais artistas da época numa pequena propriedade rural no estado de Nova York. Artistas como Rolling Stones, participantes do evento, também protestaram, por meio da música, de manifestações anti-guerra (figura 1).

\footnotetext{
4 Ícone da contracultura americana, o festival comemorou 40 anos em 20120 festival era um evento comercial, mas o número de pessoas era tanto que os organizadores não tiveram outra saída a não ser liberar a entrada de todo mundo. O clima pacífico de comemoração e a liberdade marcaram o ápice do movimento de contracultura sos anos 1960 (EVANS e KINGSBURY, 2010).
} 


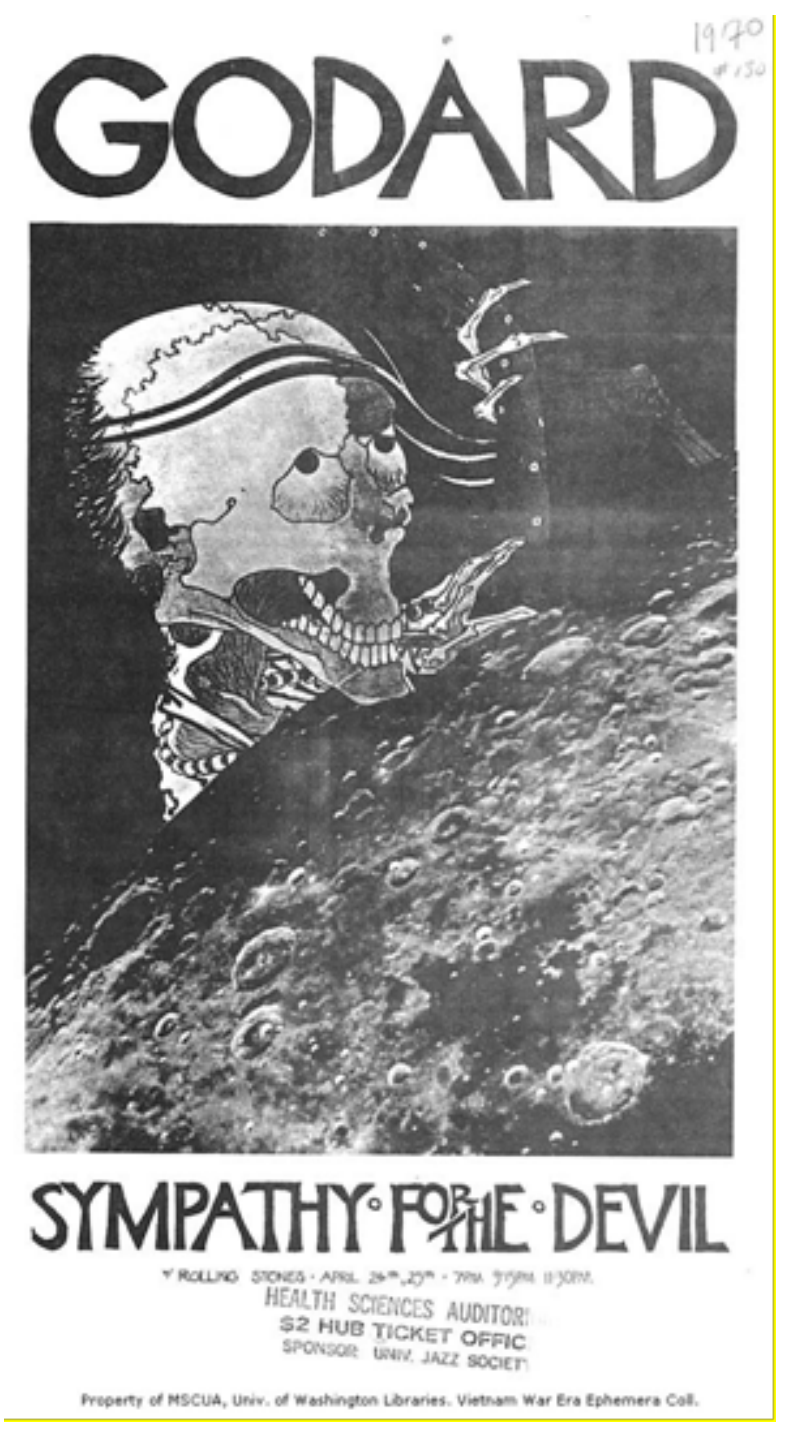

Figura 1: Panfleto criado pelo Gay Liberation Front, 1970.

Fonte: Vietnam War Era Ephemera Collection - University of Washington

Cardoso (2009) afirma que efêmero é um substantivo que se refere a algum fato ou objeto que dura um ou dois dias de um curto período de tempo. Na história da impressão gráfica, o termo efêmero escreve a classe de publicações em folhas simples ou documentos de página única que são feitos para serem descartados logo após o uso. Museus e bibliotecas ao redor do mundo passaram a coletar, organizar e preservar peças efêmeras como parte importante para a pesquisa histórica em diversos momentos. Um exemplo particularmente grande e importante dessa categoria de arquivo é a coleção de John Johnson do Printed Ephemera, na Biblioteca Bodleian , em Oxford, Inglaterra (CARDOSO, 2009).

Outro exemplo, objeto de estudo do presente artigo, é a coleção de impressos efêmeros da University of Washington, em Seattle, organizada por Kristin Kinsey e Abel Diaz entre os anos de 2003 e 2004. As peças digitalizadas e escaneadas referem-se ao contexto histórico da Guerra do Vietnã e a extensa coleção de impressos efêmeros inclui panfletos, cartazetes, manifestos, boletins informativos, folhetos e cartas abertas criadas por diversos grupos. Os criadores das peças gráficas da coleção manifestavam em prol dos direitos civis norte-americanos, bem como levantavam 
bandeiras de movimentos de protesto das décadas de 60 e 70. Como mencionado anteriormente, a coleção de impressos aborda principalmente a Guerra do Vietnã, mas inclui peças gráficas sobre feminismo, racismo, socialismo, o papel dos sindicatos e os direitos dos trabalhadores rurais, direitos dos homossexuais, boicotes ambientais e econômicos das grandes corporações e agro-indústria e direitos dos presos. Os documentos incluem as publicações de grupos como a Frente de Libertação de Seattle , Grupo de Estudantes por uma Sociedade Democrática, o Comitê de Mobilização Estudantil contrário à guerra, Jovem Aliança Socialista, Comitê de Direitos da Universidade de Washington, Frente de Libertação Gay de Seattle (figura 2), Estudantes Contra expressão violenta, entre outros. A maioria dos materiais foi criada e divulgada entre os anos de 1970 e 1973, término da guerra do Vietnã.

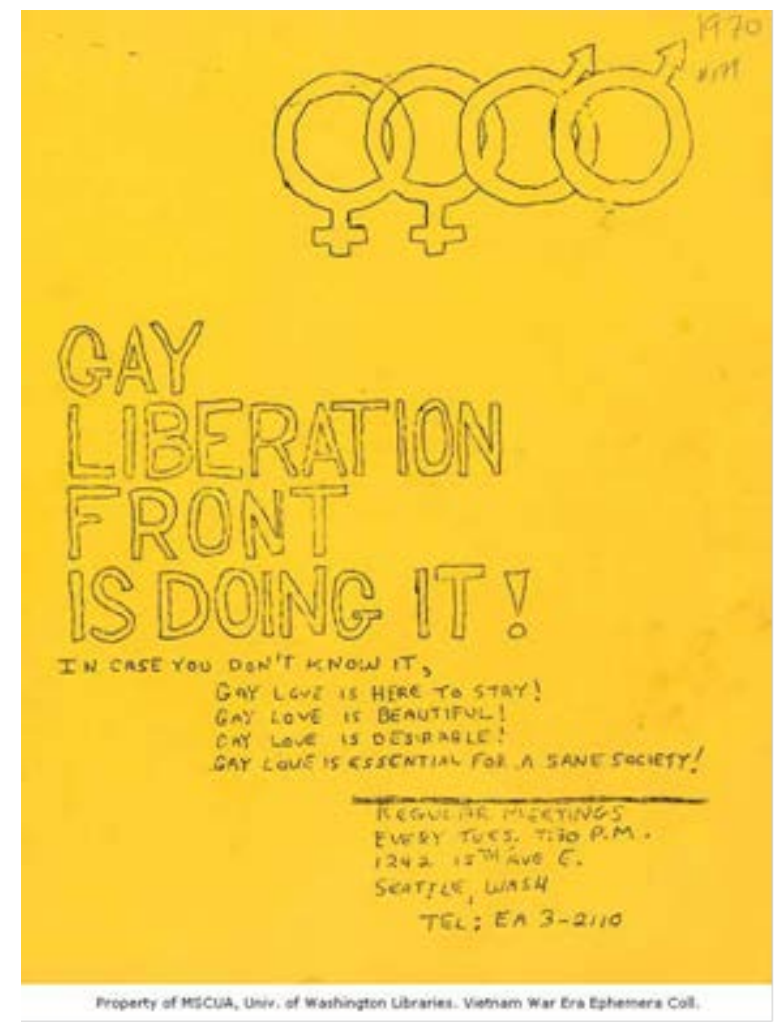

Figura 2: Panfleto criado pelo Gay Liberation Front, 1970.

Fonte: Vietnam War Era Ephemera Collection - University of Washington

Concomitante à apresentação de exemplos de impressos, faz-se necessária uma breve contextualização histórica, a fim de possibilitar a associação com os efêmeros selecionados para o artigo. Segundo Vizentini (1991) a Guerra do Vietnã foi um conflito armado que teve início em 1959 e fim em 1975. As batalhas aconteceram nos territórios do Vietnã do Norte, Vietnã do Sul, Laos e Camboja, países do sudeste asiático. O Vietnã, colônia francesa até1954, foi dividido em dois países. O Vietnã do Norte foi comnadado por Ho Chi Minh, tendo orientação comunista e favorável à URSS. O Vietnã do Sul, porém, tornou-se aliado dos Estados Unidos e, portanto, adotou o capitalismo, mas sob um regime ditatorial. A relação entre os dois Vietnãs, em decorrência das inúmeras diferenças políticas e ideológicas, era delicada no final da década de 50. Em 1959, guerrilheiros comunistas (vietcongues), comandando pelo líder Ho Chi Minh e dos aliados soviéticos, atacaram uma base norte-americana no 
Vietnã do Sul. Este evento é caracterizado como o que deu início a guerra. A Guerra do Vietnã é considerada a mais duradoura da história da civilização atual (VIZENTINI, 1991).

Com o tema "Impressos Efémeros da Guerra do Vietnã", o banco de imagens digitalizadas pela Universidade de Washington inclui uma seleção de capas e páginas internas do jornal clandestino Helix, distribuído na cena underground de Seattle (Universidade de Washington, 2013). O efeito "arco-iris" era frequentemente utilizado nos impressos do Helix, como referência à psicodelia da época, e ilustrações e gráficos eram recortadas de revistas velhas e utilizadas em novas imagens. A colagem era um recurso utilizado pelos designers e editores da publicação underground (Figura 3).

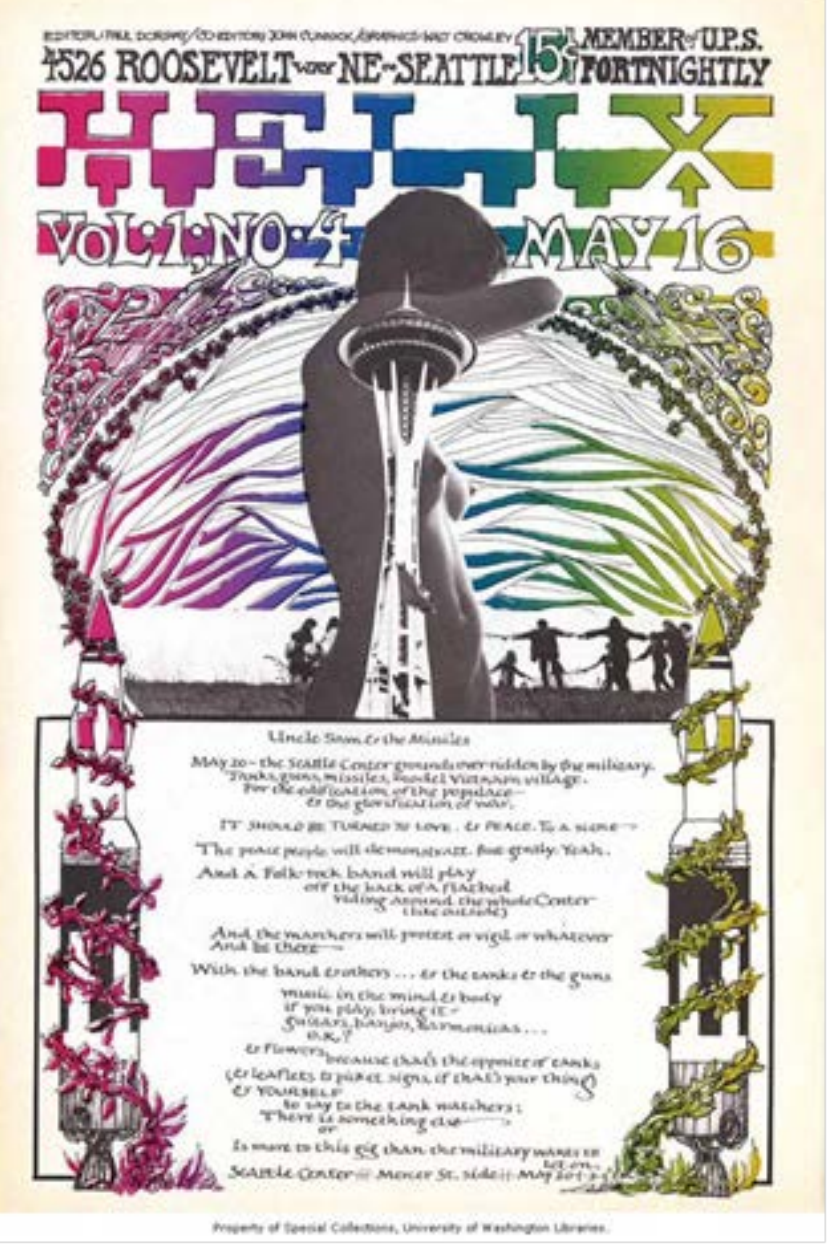

Figura 3: Capa do jornal underground Helix, 1968

Fonte: Vietnam War Era Ephemera Collection - University of Washington

Segundo Rodrigues (2006), o questionamento das formas de poder e do conceito de autoridade ocorreu de diversas maneiras, no imaginário social dos anos 70.

Paralelamente à luta armada, parte da juventude, incluindo artistas, preferiu um caminho alternativo para sua luta, como a vida comunitária, as psicodelia e experiência com drogas. Todas são assimiladas enquanto comportamento desviante (RODRIGUES, 2006). 


\section{CONSIDERAÇÕES FINAIS}

A discussão proposta pelo artigo foi a interferência do Design nas transformações sociais e como o cidadão criativo pode interferir na tomada de decisões governamentais, com o propagação de mensagens pelo uso de impressos efêmeros. O Design nasceu para criar e transmitir mensagens aos indivíduos, consumidores, eleitores, espectadores ou as pessoas que o designer pretenda atingir (BRAGA, 2011).

Cardoso (2009) afirmou que os efêmeros são, de modo geral, impressos de baixo custo e grande circulação, portanto, pouco valorizados durante I período em que forem usados. Pessoas que não excerçam ocupações rrelacionadas ao Design, Indústria gráfica ou comunicação, salvo exceções, só percebe o efêmero quando ele é retirado do seu contexto e publicado em livros ou apresentado como item de coleção, por exemplo. Ainda Segundo Cardoso (2009), devido a essa relativa invisibilidade, os impressos efêmeros são elementos reveladores de sua época, como no caso da Guerra do Vietnã, pois refletem, de certa forma, costumes, hábitos e opiniões, mas de forma impensada e viva, "revelando conceitos e preconceitos encobertos pelos livros e discurso erudito" (CARDOSO, 2009, p. 12).

Quando autores trazem temas relacionados a costumes, hábitos e opiniões, pode, então, ser traçada a relação com as vanguardas e artistas/designers importantes em suas épocas. A velocidade das vanguardas artísticas marcou as décadas de 60 , cuja capital cultural foi a cidade de Nova York. Minimalismo, Op Arte, Arte Cinética, Novo Realismo, Tropicália (Brasil) foram manifestações artísticas da época, mas a Pop Arte, surgida na Inglaterra, pode ser considerada como a mais representativa e difundida pelos norte Americanos, caracterizando-se como a vanguarda mais decisiva da década. Sem projeto, sem roteiro ou programa preestabelecido, sem manifesto, utilizando-se do repertório do dia a dia do consumo e da cultura de massa, foi transformada em tendência internacional de maneira muito rápida. Pode-se afirmar que a força da PopArt demonstrou o o poder cultural dos Americanos (GOFFMAN e JOY, 2007). No começo da década de 1970 , os protestos contra a guerra aconteciam de forma relevante nos Estados Unidos. O poder estava também nas mãos dos cidadãos, pessoas capazes de exercer forte pressão sobre o governo.

No começo da década de 1970, os protestos anti-guerra aconteciam em grande quantidade nos Estados Unidos. Muito jovens, grupos pacifistas e a população em geral se manifestavam em prol da saída dos Estados Unidos do conflito e o retorno imediato das tropas ao país. Impressos efêmeros eram distribuídos nas ruas e pessoas eram recrutadas a participar dos protestos, Neste momento, milhares eram os soldados mortos no conflito. Os meios de comunicação também exerceram um imporante papel ao noticiar a violência e crueldade da guerra.

Sem apoio popular e com derrotas seguidas, em 1975 o governo norteamericano retira a totalidade das tropas norte-americanas do Vietnã. A retirada dos EUA do conflito e a forte pressão da população contra a guerra comprovaram a existência de diferentes atores nas Relações Internacionais, que não eram apenas os Estados nem organizações Internacionais. A opinião pública e os movimentos de contracultura se colocaram como importantes fatores de intervenção nas ações dos Estados, como exemplo, os EUA que tiveram de se retirar do Vietnã pressionados pela população que se opunha fortemente a guerra. 
O presente artigo apresentou um estudo teórico e preliminar sobre como o usuário de produtos de design podem atuar como coautores de mobilizações sociais e serem responsáveis por melhorias nos seu entorno. Se a participação do usuário for considerada no momento de concepção projetual de um produto, os resultados tendem a ser positivos e os objetivos de mobilização social e melhorias, alcançados.

\section{REFERÊNCIAS}

ARFUCH, Leonor; CHAVES, Norberto; LEDESMA, María. Diseño y Comunicación. Teorías y enfoques críticos. Paidós. Buenos Aires, 1997.

BONSIEPE, Gui. "Design and Democracy". Em Design Issues, 22 (2), 2006.

BRAGA, Marcos da Costa (org.). O papel social do design gráfico. História, conceitos \& atuação profissional. Edição. 1 ed. São Paulo: Senac. 2011.

ESKILSON, Stephen. Graphic Design A New History. Londres: Laurence King, 2007.

EVANS, Mike; KINGSBURY, Paul. Woodstock: Three Days That Rocked the World. New York: Sterling, 2010.

FRASCARA, J. Diseño gráfico para la gente. Buenos Aires: Infinito, 1997.

GOFFMAN, Ken \& JOY, Dan. A contracultura através dos tempos: do mito de Prometeu à cultura digital. Rio de Janeiro: Ediouro, 2007.

GOODWIN, Robin. The Nature of Social Change. In Changing Relations: Achieving Intimacy in a Time of Social Transition. Cambridge University Press, 2010.

HEYNEMANN, Cláudia Beatriz; RAINHO, Maria do Carmo Teixeira; CARDOSO, Rafael. Marcas do progresso: consumo e design no Brasil do século XIX. Rio de Janeiro: Mauad X: Arquivo Nacional, 2009.

KOPP, R. Design Gráfico Cambiante. Santa Cruz do Sul: EDUNISC, 2002.

RODRIGUES, Jorge Luís Caê. Tinindo, Trincando: o design gráfico no tempo do desbunde. Conexão - Comunicação e Cultura, UCS, Caxias do Sul, v. 5, n. 10, jul./dez. 2006.

VIZENTINI, Paulo G. Fagundes. Guerra do Vietname: Descolonização e revolução. 2a ed. Porto Alegre: Ed. UFRGS, 1991.

\section{REFERÊNCIAS DE INTERNET}

Vietnam War Era Ephemera Collection - University of Washington. Disponível em http://content.lib.washington.edu/protestsweb/index.html. Acesso em 10/10/2013.

The Designer Observer Group. Disponível em http://observatory.designobserver.com/entry.html?entry=25378. Acesso em 10/10/2013. 